\title{
Regulation of Experimental Autoimmune Encephalomyelitis with Insulin-like Growth Factor (IGF-1) and IGF-1/IGF-binding Protein-3 Complex (IGF-1/IGFBP3)
}

\author{
Amy E. Lovett-Racke, Patrice Bittner, Anne H. Cross, Joseph A. Carlino, and Michael K. Racke \\ Department of Neurology, Washington University School of Medicine, St. Louis, Missouri 63110
}

\begin{abstract}
Insulin-like growth factor (IGF)-1 is a cytokine that promotes oligodendrocyte development and myelin production. This study investigated whether treatment of chronic, relapsing murine experimental autoimmune encephalomyelitis (EAE) with IGF-1 or IGF-1 associated with its binding protein, IGFBP3, altered the course of disease. Administration of IGF-1/IGFBP3 (1-100 $\mathrm{mg} / \mathrm{kg}$ per day) delayed the onset of disease in a dose-dependent manner and histologic examination showed a delay in inflammatory cells entering the central nervous system. However, once signs of EAE developed, disease was enhanced in the mice that had been given the highest dose of IGF-1/IGFBP3. Treatment with IGF-1/IGFBP3 after the onset of signs resulted in a severe relapse. Administration of free IGF-1 (10 mg/kg per day) provided mild protection when given before disease onset, but did not significantly alter the course of disease if given after disease onset. Possible mechanisms that could explain the altered disease in IGF-1/IGFBP3-treated mice included (a) IGF-1/IGFBP3 administration delayed the onset of EAE by downregulating ICAM-1 gene expression in the central nervous system, and (b) IGF-1/IGFBP3 treatment of EAE resulted in more severe disease due to enhanced expansion of encephalitogenic T cells. Although IGF-1 may enhance remyelination, these results indicate that administration of IGF-1 associated with IGFBP3 may also accentuate autoimmune demyelinating disease. (J. Clin. Invest. 1998. 101: 1797-1804.) Key words: autoimmunity • multiple sclerosis • growth factors • neuroimmunology
\end{abstract}

\section{Introduction}

Experimental allergic encephalomyelitis (EAE) $)^{1}$ is an autoimmune disorder characterized by relapsing paralysis and central nervous system (CNS) inflammation and demyelination, fea-

\footnotetext{
Address correspondence to Michael K. Racke, Department of Neurology, Washington University School of Medicine, Box 8111, 660 South Euclid Avenue, St. Louis, MO 63110. Joseph A. Carlino's present address is Chiron Corporation, 4560 Horton Street, Emeryville, CA 94608-2916.

Received for publication 13 August 1997 and accepted in revised form 13 February 1998.
}

1. Abbreviations used in this paper: CNS, central nervous system; DPT, days post transfer; EAE, experimental allergic encephalomyelitis; HPRT, hypoxanthine phosphoribosyl transferase; LNC, lymph node cells; MBP, myelin basic protein; TCR, T cell receptor.

J. Clin. Invest.

(C) The American Society for Clinical Investigation, Inc. 0021-9738/98/04/1797/08 \$2.00

Volume 101, Number 8, April 1998, 1797-1804

http://www.jci.org tures reminiscent of the human disease, multiple sclerosis (1). In mice, EAE can be induced in susceptible strains by the adoptive transfer of myelin basic protein (MBP)-specific $\mathrm{CD}^{+}$, class II MHC-restricted T cells into naive, syngeneic recipients (2-4). Precise knowledge of the T cell receptor (TCR) and encephalitogenic epitopes involved in EAE has led to a number of therapeutic strategies that may have potential in the treatment of human demyelinating diseases (5-9).

An alternative approach by our laboratory has been to explore potential therapies where the precise knowledge of TCR and antigen is not essential, as knowledge of the components of the trimolecular complex would be necessary to implement these therapeutic strategies in human disorders. Specifically, we have demonstrated that cytokines such as transforming growth factor- $\beta$ and IL-4, which are important regulators of inflammation, can be effective therapeutic agents in the EAE model $(3,4)$.

Another approach to the treatment of inflammatory demyelination would be to treat with a cytokine or growth factor that promotes remyelination. IGF-1 is such a molecule. IGF-1 is a single-chain polypeptide with structural homology to proinsulin that is produced by many tissues and is abundant in the circulation. IGF-1 regulates the proliferation and differentiation of many cell types (reviewed in 10,11). IGF-1 is a potent stimulator of myelination in vitro and a potent inducer of oligodendrocyte development (12-14). Transgenic expression of IGF-1 resulted in increased brain growth and CNS myelination, whereas disruption of the IGF-1 gene resulted in reduced brain size and CNS hypomyelination $(15,16)$. Interestingly, expression of IGF-1 and one of its binding proteins (IGFBP2) by astrocytes in the CNS has been demonstrated in a number of CNS injury models, including EAE (17-21).

Recent work has demonstrated that administration of IGF-1 can reduce the clinical deficits and lesion severity in the Lewis rat model of EAE, a model which is predominantly monophasic $(18,20)$. In addition to reducing clinical signs of disease, synthesis of myelin proteins was enhanced after IGF-1 treatment (20). Because IGF-1 administration can result in hypoglycemia through its interaction with insulin receptors, we decided to study both IGF-1 and IGF-1 bound to its major serum-binding protein, IGFBP3 in a chronic, relapsing model of murine EAE. Systemic administration of IGF-1/IGFBP3 results in the binding of this complex to endogenous free acid labile subunit, and increased circulation of this stable ternary complex (22). Thus, when compared to systemic dosing of free IGF-1, systemic dosing of IGF-1/IGFBP3 results in increased systemic exposure to IGF-1, due to its longer circulating halflife. However, binding of IGF-1/IGFBP3 to the acid labile subunit slows the release of IGF-1 from the vascular compartment, resulting in protection from side effects such as hypoglycemia (22).

In the present study, because cells of the immune system also have receptors for IGF-1, we examined the effects of IGF-1 and IGF-1/IGFBP3 on immune cells in the EAE model. In particular, we examined the effects of IGF-1 and IGF-1/ 
IGFBP3 on antigen-specific $\mathrm{T}$ cell proliferation, cytokine secretion, and its effects on clinical outcome in the EAE model, a prototypic model of organ-specific autoimmunity. Furthermore, the adoptive transfer model of murine EAE was used in these studies because it allows the investigation of both the activation of encephalitogenic $\mathrm{T}$ cells in vitro and the mechanisms involved in the production of EAE in vivo. Because IGF-1 is being considered as a therapeutic agent for a number of different pathological human conditions, including multiple sclerosis, the results presented may have relevance for the eventual use of IGF-1 in human diseases $(18,20,23,24)$.

\section{Methods}

Mice. $(\mathrm{PL} \times \mathrm{SJL}) \mathrm{F} 1$ mice were obtained from The Jackson Laboratory (Bar Harbor, ME) at 4-6 wk of age. All mice were 8-10 wk old when experiments were initiated. All procedures were performed under an approved protocol in compliance with guidelines set by the Animal Studies Committee of the Washington University School of Medicine (St. Louis, MO).

Reagents. MBP was prepared from guinea pig spinal cords (Rockland Inc., Gilbertville, PA) as previously described (25). The human recombinant IGF-1 and IGF-1/IGFBP3 used in these studies were produced in Escherichia coli using an inducible T7 RNA polymerase/translational coupler expression system and provided by Celtrix Pharmaceuticals (Santa Clara, CA; JAC) (26). Endotoxin levels in both preparations were $<0.1 \mathrm{EU} / \mathrm{ml}$. IGFBP3 was chosen as the binding protein for these studies because it is the predominant IGFBP in serum and because systemic administration of the IGF-1/ IGFBP3 complex has greater potency and fewer side effects than systemic administration of IGF-1 alone (22).

Adoptive transfer of EAE. $(\mathrm{PL} \times \mathrm{SJL}) \mathrm{F} 1$ mice were immunized s.c. with $0.1 \mathrm{ml}$ of an emulsion containing equal volumes of MBP (8 $\mathrm{mg} / \mathrm{ml}$ in PBS) and CFA (Difco Laboratories, Detroit, MI), and after $10 \mathrm{~d}$ draining lymph nodes were harvested. Lymph nodes were homogenized into a single cell suspension and cultured $\left(4 \times 10^{6}\right.$ cells $\left./ \mathrm{ml}\right)$ for $4 \mathrm{~d}$ with MBP $(25 \mu \mathrm{g} / \mathrm{ml})$ in RPMI 1640 medium containing $10 \%$ FBS, glutamine, nonessential amino acids, sodium pyruvate, 2-mercapto-ethanol, Hepes, and penicillin/streptomycin, as previously described (2-4). After the culture period, MBP-activated lymph node cells were washed, and injected intravenously $\left(3 \times 10^{7}\right.$ cells $/ 0.2 \mathrm{ml}$ PBS) into naive, syngeneic recipients. Mice were examined daily for signs of disease by a blinded examiner and graded on the following scale: 0 , no abnormality; 1 , a limp tail; 2 , moderate hind limb weakness; 3 , severe hind limb weakness; 4 , complete hind limb paralysis; 5, quadriplegia or premoribund state; 6 , death (2-4).

Treatment of mice with EAE by IGF-1 or IGF-1/IGFBP3. Mice were divided into treatment groups that included mice receiving either IGF-1, IGF-1/IGFBP-3, or placebo at the doses and days indicated in the tables and figure legends. Mice received two doses of reagent $8 \mathrm{~h}$ apart on the same day by intraperitoneal injection.

Lymphocyte proliferation. Proliferative responses were assessed routinely on MBP-specific lymph node cells (LNC) by incubating LNC $\left(2 \times 10^{5}\right.$ cells/well $)$ with MBP $(25 \mu \mathrm{g} / \mathrm{ml})$, Con A $(4 \mu \mathrm{g} / \mathrm{ml})$, or no antigen in the presence or absence of serial dilutions of IGF-1 or IGF-1/IGFBP3. The cultures were maintained in 96-well flat-bottomed microtiter plates (Falcon Plastics, Lincoln Park, NJ) for $4 \mathrm{~d}$ at $37^{\circ} \mathrm{C}$ in $5 \% \mathrm{CO}_{2}$-air. The wells were pulsed with $0.5 \mu \mathrm{Ci} /$ well of $\left[{ }^{3} \mathrm{H}\right]$ methyl-thymidine (Amersham Corp., Arlington Heights, IL) for the final $16 \mathrm{~h}$ of incubation. Cells were harvested onto glass-fiber filters using a Tomtec (Orange, CT) 96-well cell harvester, and filters were assayed for incorporated thymidine using a 1205 Betaplate liquid scintillation counter (Wallac, Gaithersburg, MD). Results were determined as arithmetic means from quadruplicate cultures.

Cytokine and adhesion molecule gene expression. For CNS tissue, the brains and spinal cords were removed and total RNA extracted using TRIzol (Life Technologies, Grand Island, NY). For lymphocytes, RNA was extracted using TRIzol after $18 \mathrm{~h}$ of in vitro culture. For each RNA sample, $2.5 \mu \mathrm{g}$ was reversed transcribed using the T-primed First-strand Ready-to-go kit (Pharmacia Biotech, Uppsala, Sweden) with an additional $0.2 \mu \mathrm{g}$ of random primers. ICAM-1, VCAM-1, IFN- $\gamma$, IL-2, IL-4, and IL-10 cDNA were amplified by PCR using previously described oligonucleotide primers $(27,28)$. For VLA-4 and LFA-1, the following primers and probes were used: LFA-1 primers, 5'-GTCTCAGAGCTACAGGGTGACC-3' and 5'-CACCTCGTGCACTGGGATTTC-3', LFA-1 internal probe, 5' AGCAGGGTGCTGTGTACATCTTC-3'; VLA-4 primers, 5' -ACGCTGTTTGGCTACTCGGTGGT-3' and 5'-AGCTGGAGCTGTTCGCAGGTCT-3', VLA-4 internal probe, 5'-GCTCTCTAATGCCTCAGTGGTCAA- $3^{\prime}$. The PCR reactions included $1 / 20$ of each cDNA sample, $5 \mu \mathrm{M}$ of each primer, $200 \mu \mathrm{M}$ dNTPs (Perkin-Elmer, Foster City, CA), and 1.25 U of Taq polymerase (Life Technologies Inc., Gaithersburg, MD) in buffer supplied by the polymerase manufacturer in a final volume of $50 \mu \mathrm{l}$. The PCR conditions were $1 \mathrm{~min}$ at $94^{\circ} \mathrm{C}, 1 \mathrm{~min}$ at $55^{\circ} \mathrm{C}$, and $1.5 \mathrm{~min}$ at $72^{\circ} \mathrm{C}$ for 25 (adhesion molecules) or 30 cycles (cytokines). These conditions resulted in PCR products that were below detection by ethidium bromide, and consequently below the saturation point of the reaction. To control for the quantity and quality of each cDNA sample, hypoxanthine phosphoribosyl transferase (HPRT) gene expression was also determined for each cDNA. Values for specific adhesion molecules and cytokines were normalized to HPRT values. Amplified PCR products were detected by Southern blot analysis using ${ }^{32} \mathrm{P}$-labeled oligonucleotide probes and the resulting signals were quantitated with a Phosphorimager (Molecular Dynamics, Sunnyvale, CA).

Neuropathology. Anesthetized animals were perfused through the left cardiac ventricle with $2.5 \%$ buffered glutaraldehyde, as described (29). Briefly, CNS tissue was removed and $\sim 1$-mm slices were made of all levels of the neuraxis. These were postfixed in cold $1 \%$ osmium tetroxide for $1 \mathrm{~h}$, dehydrated in a series of ethyl alcohols, and embedded in epoxy resin (EMBED 812; Electron Microscopy Sciences, Fort Washington, PA). 1- $\mu \mathrm{m}$ epoxy sections of tissue from all groups were stained with toluidine blue and examined by light microscopy in a blinded fashion by a single observer (A.H. Cross). Sections were scored for inflammation, demyelination, remyelination, and axonal necrosis, using a published scoring system (30).

Statistical methods. Treatment effects were assessed by using a multivariate approach (Hotellings $\mathrm{T}^{2}$ ), which takes into account the correlation across time in comparing the resulting curves, and by the Mann-Whitney sum of ranks test $(3,4,31)$. The Hotellings test addresses whether a treatment has had a significant effect on the course of a relapsing disease, whereas the Mann-Whitney test addresses differences in clinical score during the observation period.

\section{Results}

Prevention of EAE with IGF-1/IGFBP3. In our initial experiments, we tested the amount of free IGF-1 and IGF-1/IGFBP3 that could be administered to $(\mathrm{PL} \times \mathrm{SJL}) \mathrm{F} 1$ mice without any observable signs of hypoglycemia. Published reports using Lewis rats had demonstrated that doses of $3.0 \mathrm{mg} / \mathrm{kg}$ per day of free IGF-1 were both safe and efficacious $(18,20)$. Our initial pharmacodynamic studies showed that we could give $10 \mathrm{mg} / \mathrm{kg}$ per day of free IGF-1 and $100 \mathrm{mg} / \mathrm{kg}$ per day of IGF-1/IGFBP3 to $(\mathrm{PL} \times \mathrm{SJL}) \mathrm{F} 1$ mice in two daily intraperitoneal injections without clinical signs of hypoglycemia (data not shown). Because approximately one-fifth of the molecular weight of the IGF-1/IGFBP3 complex is due to IGF-1 itself, the $100 \mathrm{mg} / \mathrm{kg}$ per day dose of the complex is the molar equivalent of $20 \mathrm{mg} /$ kg per day of free IGF-1.

We then addressed the effects of IGF-1 and IGF-1/IGFBP3 administration on $(\mathrm{PL} \times \mathrm{SJL}) \mathrm{F} 1$ mice in a relapsing model of 

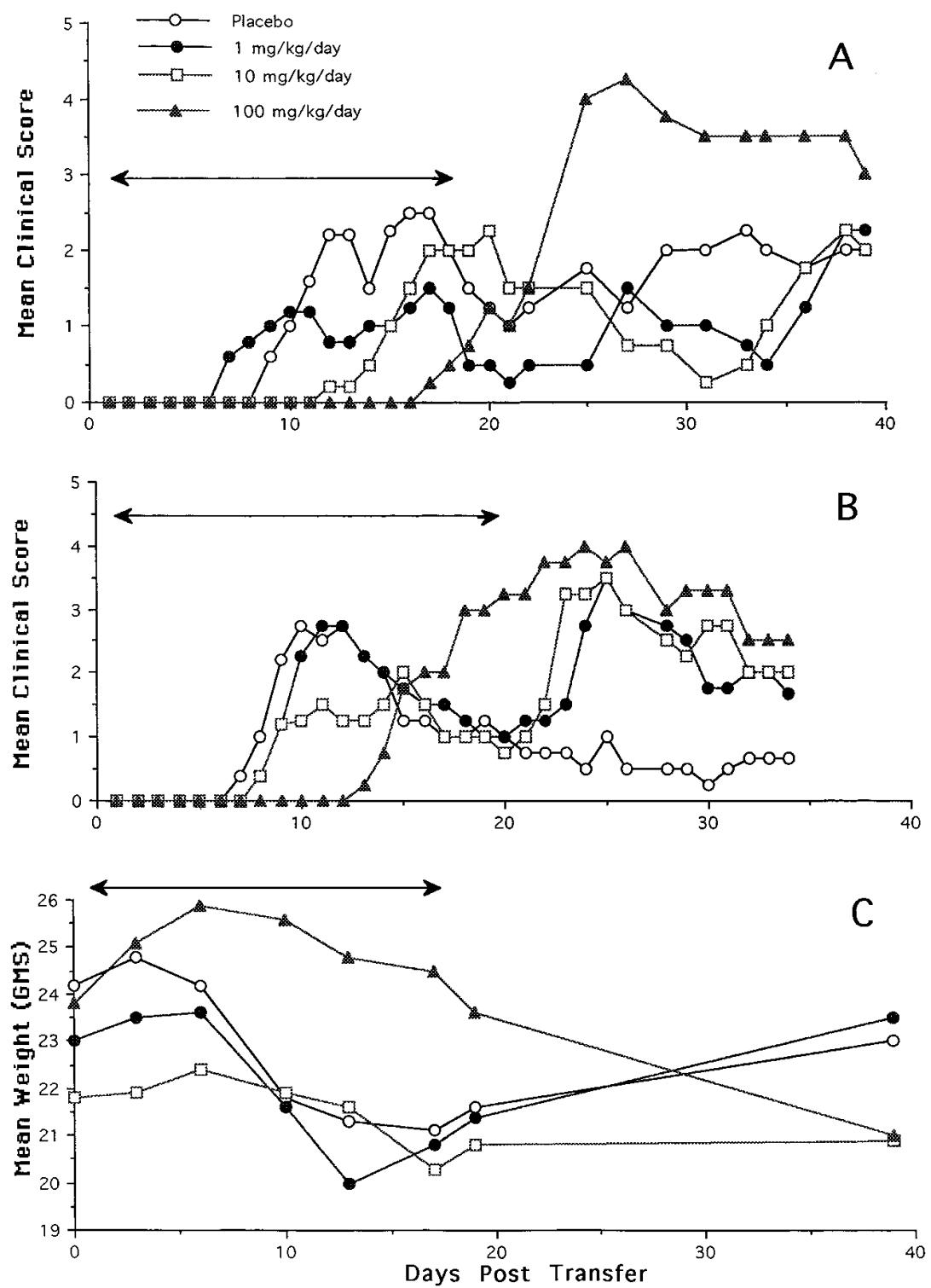

Figure 1. Administration of IGF-1/IGFBP3 in EAE. Activated LNC from MBP/CFA-immunized mice were transferred into naive recipients at day 0 . Recipient mice received IGF-1/IGFBP3 $(\bullet, 1 \mathrm{mg} / \mathrm{kg}$ per day; $\square, 10 \mathrm{mg} / \mathrm{kg}$ per day; and $\boldsymbol{\Lambda}$, $100 \mathrm{mg} / \mathrm{kg}$ per day) or placebo $(\bigcirc)$ intraperitoneally from days 1-17 in $A$ and from days 1-20 in $B$, as noted by the doubleheaded arrow. In $A$ and $B$, mice were monitored daily and a mean clinical score was assigned for each group of five mice. In $C$, mean weights of mice from experiment $A$ are shown. In $A$ and $B$, placebo and $100 \mathrm{mg} / \mathrm{kg}$ per day treatment groups were significantly different by Hotellings $\mathrm{T}^{2}$ analysis $(P<0.05)$. In $A$, using Mann-Whitney sum of ranks analysis, both the $1 \mathrm{mg} / \mathrm{kg}$ per day $(P=0.022)$ and the $10 \mathrm{mg} / \mathrm{kg}$ per day $(P=0.046)$ doses of IGF-1/IGFBP3 provided significant protection compared to placebo. In $B$, using similar analysis, the $1 \mathrm{mg} / \mathrm{kg}$ per day dose $(P=0.020)$ and the $10 \mathrm{mg} / \mathrm{kg}$ per day $(P=0.038)$ dose exacerbated disease compared to placebo. In both $A$ and $B$, there was no significant difference in disease scores comparing the $100 \mathrm{mg} / \mathrm{kg}$ per day dose of IGF-1/IGFBP3 with placebo. The differences in outcome from the different statistical analyses when comparing the placebo group with the high dose IGF-1/IGFBP3 highlight the fact that IGF-1/IGFBP3 (100 mg/kg per day) changed the course of disease, yet both groups experienced similar cumulative disease scores over the period of observation.
EAE. In initial studies, IGF-1/IGFBP3 was administered to mice for either 17 or $20 \mathrm{~d}$ after the adoptive transfer of encephalitogenic T cells (Fig. 1). With the administration of IGF-1/ IGFBP3, the onset of EAE was inhibited in a dose-dependent manner. As seen in Fig. $1 A$, mice that received the highest dose of IGF-1/IGFBP3 (100 mg/kg per day) were protected from the onset of disease for $8 \mathrm{~d}$, compared to mice receiving placebo. However, this group developed a much more severe clinical disease once signs of disease did occur (Fig. $1 A$ ). A similar experiment demonstrated exacerbation of late disease at all doses tested, in a dose-dependent fashion (Fig. $1 B$ ). In agreement with the clinical scores, mice receiving the highest dose of IGF-1/IGFBP3 maintained their body weight for a longer period of time than mice receiving placebo or lower doses of IGF-1/IGFBP3, consistent with the known anabolic effects of IGF-1. However, upon developing clinical signs of EAE, these mice lost weight (Fig. $1 C$ ).

Histologic examination of mice receiving IGF-1/IGFBP3. Mice from the experiments shown in Fig. 1 were killed and un- derwent histopathologic examination. Mice that received the highest doses of IGF-1/IGFBP3, all of which had delayed onset of disease, showed minimal infiltration of the CNS by inflammatory cells before the onset of clinical signs of disease (Fig. 2, $A$ and $C$; Table I). However, animals receiving this same treatment regimen $(100 \mathrm{mg} / \mathrm{kg}$ per day) went on to develop severe EAE, and these mice exhibited increased inflammation, demyelination, and axonal necrosis compared to mice receiving lower doses of IGF-1/IGFBP3 or placebo (Fig. 2, $B$ and $D$; Table I, Exp. 1, 49 days post transfer (DPT); Exp. 2, 31 DPT).

Comparison of IGF-1 and IGF-1/IGFBP3 in both the prevention and treatment of $E A E$. Because administration of IGF-1/IGFBP3 resulted in an accentuation of the clinical signs and pathology of EAE, although delayed, experiments were performed in which free IGF-1 and IGF-1/IGFBP3 complex were administered in equimolar amounts. Administration of free IGF-1 (10 mg/kg per day) from days 0-7 did provide mild protection, whereas IGF-1/IGFBP3 (50 mg/kg per day) did not 

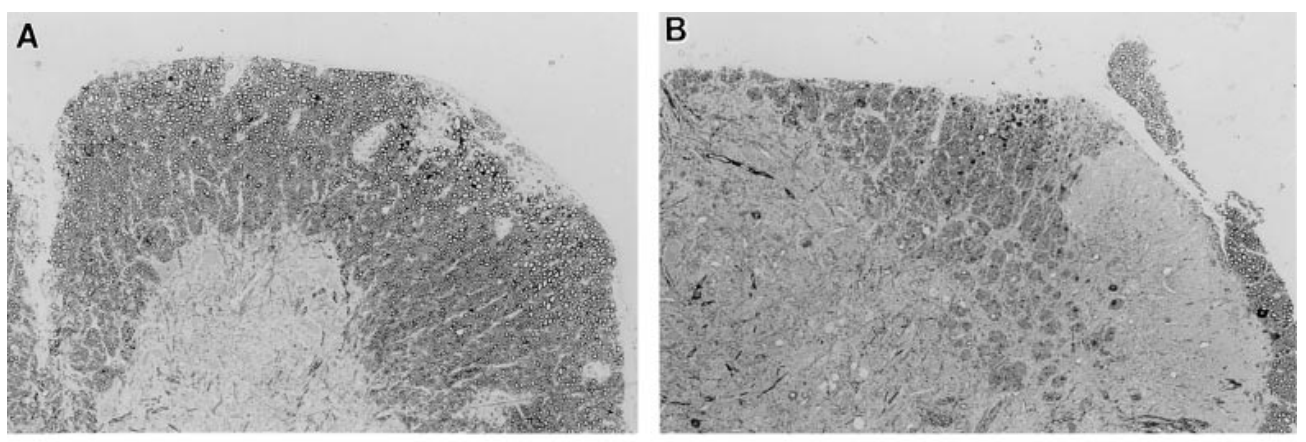

Figure 2. Representative 1- $\mu \mathrm{m}$ CNS sections from IGF-1/ IGFBP3-treated and controltreated mice stained with toluidine blue. All $\times 42$. $(A)(\mathrm{PL} \times$ SJL)F1 mouse at 10 DPT (clinical grade 2), treated with placebo for previous $10 \mathrm{~d}$. Anterior aspect of section taken from the lumbar spinal cord region shows extensive inflammation and some demyelination. $(B)(\mathrm{PL} \times$ SJL)F1 mouse at 49 DPT (clini-
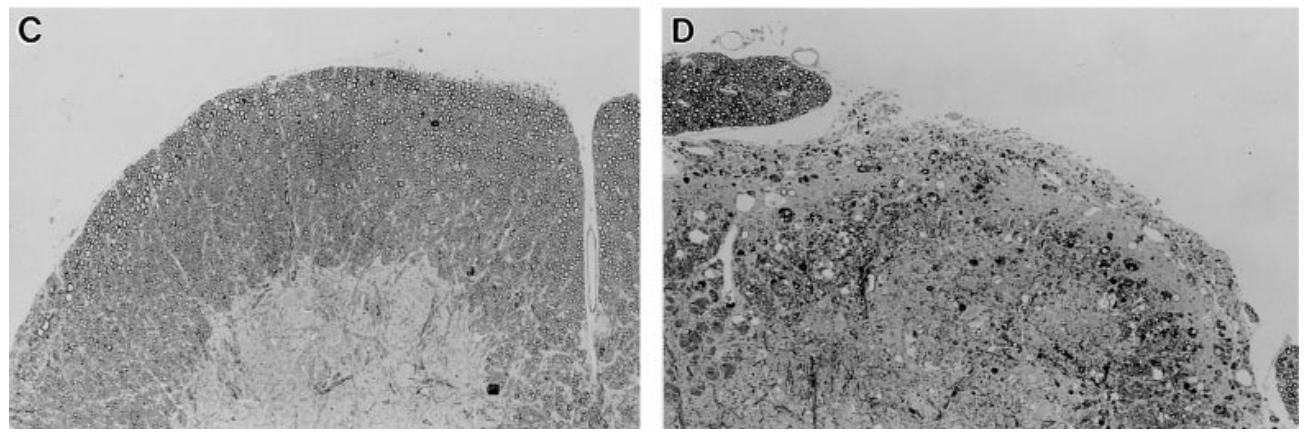
cal grade 3), treated with placebo from 0-20 DPT. A mild degree of Wallerian degeneration is noted within the posterolateral columns. There was also meningeal and perivascular inflammation within the posterior columns, not shown in this view. (C) $(\mathrm{PL} \times \mathrm{SJL}) \mathrm{F} 1$ mouse at 10 DPT (clinical grade 0 ), treated with IGF-1/IGFBP3 for previous $10 \mathrm{~d}$ at $100 \mathrm{mg} / \mathrm{kg}$ per day. A section of the anterior and anterolateral columns at the lower lumbar level shows normal spinal cord anatomy without inflammation, demyelination, or axonal loss. $(D)(\mathrm{PL} \times$ SJL)F1 mouse at 49 DPT (clinical grade 3), treated with IGF-1/IGFBP3 (100 mg/kg per day) from 0-20 DPT. A section from the lower lumbar spinal level (same region as in $B$ ) shows a large demyelinated region, meningeal and perivascular inflammation, and numerous lost axons.

Table I. Histopathology of IGF-1/IGFBP3 Treated Mice*

\begin{tabular}{|c|c|c|c|c|c|c|}
\hline Exp. & DPT & $\begin{array}{c}\text { Dose } \\
\text { (mg/kg per day) }\end{array}$ & Inflammation & Demyelination & Remyelination & $\begin{array}{l}\text { Axonal } \\
\text { necrosis }\end{array}$ \\
\hline \multirow[t]{8}{*}{1} & \multirow[t]{4}{*}{13} & 0 & +++ & + & 0 & ++ \\
\hline & & 1 & ++ & + & \pm & + \\
\hline & & 10 & $+\ddagger$ & \pm & 0 & \pm \\
\hline & & 100 & 0 & 0 & 0 & 0 \\
\hline & \multirow[t]{4}{*}{49} & 0 & +++ & +++ & 0 & +++ \\
\hline & & 1 & +++ & ++ & ++ & ++ \\
\hline & & 10 & ++ & ++ & \pm & ++ \\
\hline & & 100 & ++ & +++ & + & +++ \\
\hline \multirow[t]{8}{*}{2} & \multirow[t]{4}{*}{10} & 0 & ++ & + & 0 & + \\
\hline & & 1 & + & 0 & 0 & 0 \\
\hline & & 10 & + & + & 0 & 0 \\
\hline & & 100 & \pm & \pm & 0 & 0 \\
\hline & \multirow[t]{4}{*}{31} & 0 & ++ & ++ & \pm & ++ \\
\hline & & 1 & ++ & ++ & \pm & ++ \\
\hline & & 10 & ++ & ++ & + & +++ \\
\hline & & 100 & +++ & +++ & \pm & +++ \\
\hline
\end{tabular}

* Mice received $3 \times 10^{7} \mathrm{MBP}$-specific LNC on day 0 and then received $17 \mathrm{~d}$ (Exp. 1) or $20 \mathrm{~d}$ (Exp. 2) of IGF-1/IGFBP3 at the dose indicated $(0=$ placebo control). Mice were killed on the day indicated and underwent histologic examination. The extent of demyelination, remyelination, or axonal necrosis was graded according to the following scoring system: - , no demyelination, remyelination, or axonal necrosis; \pm , a few, scattered, affected axons; + , small groups of affected axons; ++ , large groups of affected axons; +++ , confluent foci of demyelination, remyelination, or axonal necrosis (30). "Inflammation, demyelination, and axonal necrosis were noted only in the lumbosacral cord. The rest of the CNS was free of inflammation. provide significant clinical benefit (Fig. $3 A$ ). Interestingly, repeating the same doses after the onset of clinical signs of disease (days 12-20) resulted in a dramatic relapse in mice receiving the IGF-1/IGFBP3 complex, whereas mice receiving free IGF-1 had a similar disease course compared to mice that had received placebo (Fig. $3 B$ ).

Effects of free IGF-1 and IGF-1/IGFBP3 on proliferation, cytokine production, and encephalitogenicity of MBP-specific LNC. Because T cells are known to have receptors for IGF-1 $(32,33)$, experiments were performed to examine whether IGF-1 or IGF-1/IGFBP3 had any effects on the development of encephalitogenic precursors in vitro. Both IGF-1 and IGF-1/ IGFBP3 enhanced the proliferation of MBP-specific LNC, with the IGF-1/IGFBP3 complex doing so more effectively at higher doses (Fig. 4). Examination of the gene expression of several cytokines implicated in the pathogenesis of EAE and lymphocyte differentiation showed that the presence of IGF-1 or IGF-1/IGFBP3 did not alter the lymphokine-secreting phenotype of the MBP-specific LNC (Fig. 5). These data support the concept that the exacerbation of $\mathrm{EAE}$ in mice receiving the high dose of IGF-1/IGFBP3 may be due to the expansion of encephalitogenic T cells in vivo.

Although culture of MBP-specific LNC, with either free IGF-1 or IGF-1/IGFBP3 alone, mildly enhanced proliferation in the absence of antigen, it was not sufficient to activate most encephalitogenic precursors in vitro, based on disease-inducing effect (Table II). However, activation of MBP-specific LNC with antigen in the presence of either free IGF-1 or IGF1/IGFBP3 did not inhibit encephalitogenic potential. In the case of free IGF-1, the encephalitogenic potential of MBP-specific LNC may actually have increased, as two of the three mice receiving LNC cultured with MBP and free IGF-1 died 

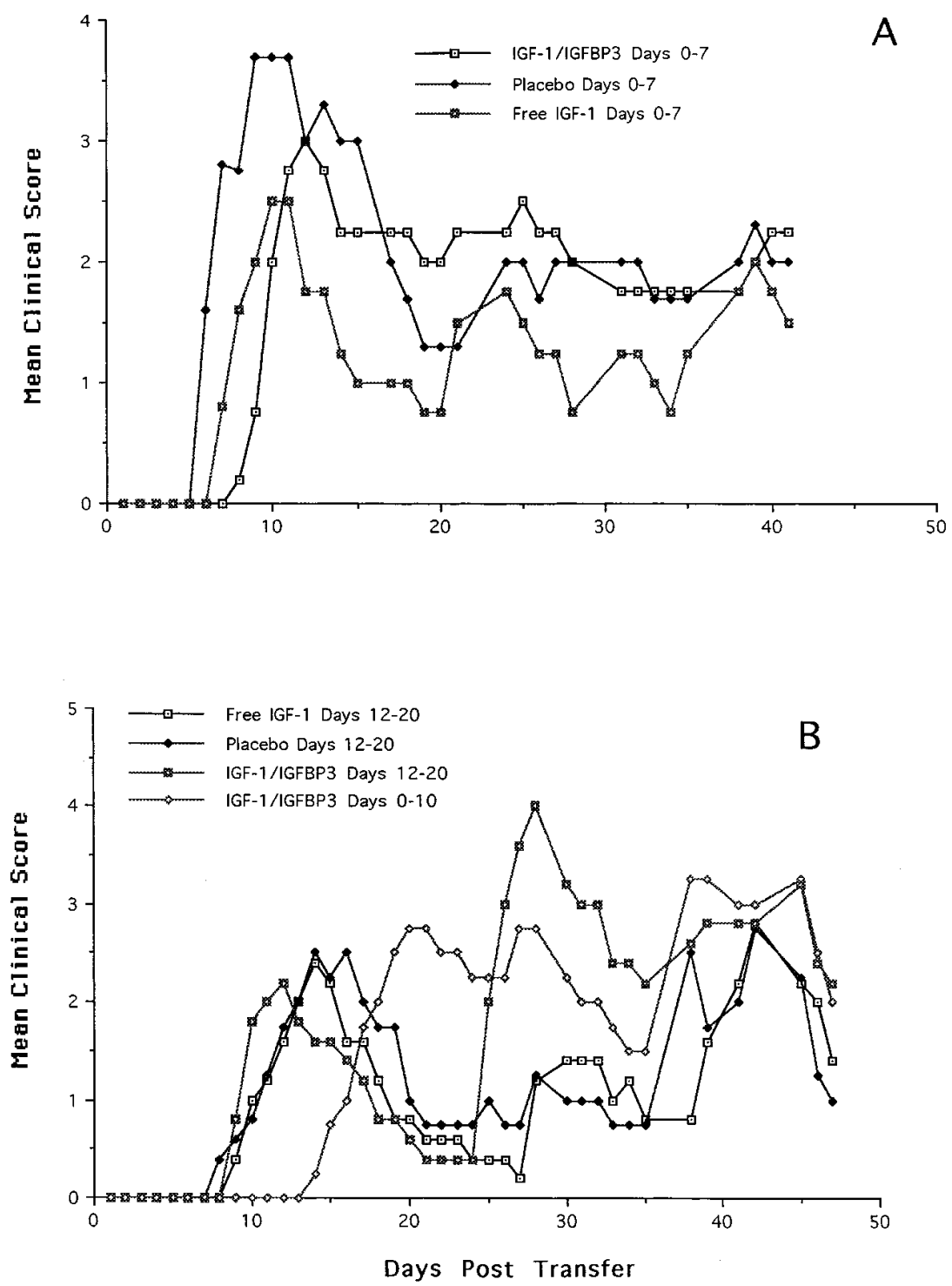

Figure 3. Comparison of IGF-1 and IGF-1/ IGFBP3 treatment in EAE. Activated LNC from $\mathrm{MBP} / \mathrm{CFA}$-immunized mice were transferred into naive recipients at day 0 . Mice received free IGF-1 $(10 \mathrm{mg} / \mathrm{kg}$ per day), IGF-1/IGFBP3 $(50 \mathrm{mg} / \mathrm{kg}$ per day), or placebo on the days indicated. These doses represent equimolar amounts of IGF-1. Mice were monitored daily and a mean clinical score was assigned for each group of five mice. No significant difference was noted between IGF-1 and placebo-treated mice by Hotellings analysis. In $B$, both IGF-1/IGFBP3 groups are significantly different from placebo by Hotellings $\mathrm{T}^{2}$ analysis $(P<0.05)$. In $A$, using Mann-Whitney sum of ranks analysis, free IGF-1 provided significant clinical benefit compared to placebo $(P=0.0001)$, whereas IGF-1/IGFBP3 showed no benefit. In $B$, there was no significant difference between free IGF-1 and placebo, whereas IGF-1/IGFBP3 given on days $12-20$ significantly worsened disease $(P=$ 0.043) using Mann-Whitney analysis.

from severe EAE, whereas no mortality was observed in any of the other treatment groups. On the other hand, disease onset was delayed mildly in mice receiving MBP-specific LNC cultured in the presence of MBP and IGF-1/IGFBP3 (Table II).

Delay in onset of EAE after IGF-1 or IGF-1/IGFBP3 correlated with inhibition of ICAM-1 expression in the CNS. Because application of IGF-1 or IGF-1/IGFBP3 complex to MBP-specific T cells in vitro did not eliminate the ability of the $\mathrm{T}$ cells to enter the CNS and cause disease, experiments were performed to examine whether IGF-1 or IGF-1/IGFBP3 affected the expression of adhesion molecules in the CNS. Administration of either IGF-1 or IGF-1/IGFBP3 inhibited the expression of ICAM-1 in the spinal cord, yet did not affect the expression of VCAM-1 (Fig. 6). This suggested that inhibition of ICAM-1 expression on CNS endothelium may have played a role in the delay of clinical signs of disease and inhibition of inflammation early in the course of disease by high doses of IGF-1/IGFBP3 (Fig. 1, Table I). The ability of IGF-1 or IGF-1/ IGFBP3 to alter adhesion molecule gene expression by encephalitogenic $\mathrm{T}$ cells in vitro was also examined. No signifi- cant alteration in gene expression for LFA-1 and VLA-4, the ligands of ICAM-1 and VCAM-1, was noted (data not shown), suggesting that the IGF-1/IGFBP3 administered only affected adhesion molecule expression in the target organ, the CNS.

\section{Discussion}

We examined the effects of IGF-1 and IGF-1/IGFBP3 in a chronic, relapsing model of murine EAE. Prior studies in the Lewis rat model of EAE had demonstrated that administration of free IGF-1 at doses of 0.6 and $3.0 \mathrm{mg} / \mathrm{kg}$ per day resulted in a more rapid recovery from paralysis and this effect was dose-dependent $(18,20)$. Because there were several lines of evidence to show that IGF-1 might promote remyelination, the investigators showed that IGF-1 administration resulted in increased expression of myelin-related proteins, suggesting that increased remyelination may be one mechanism for the observed clinical benefit (20). However, another observation in those studies was that the number of lesions and lesion area was reduced in rats that had received IGF-1 (18). Because 


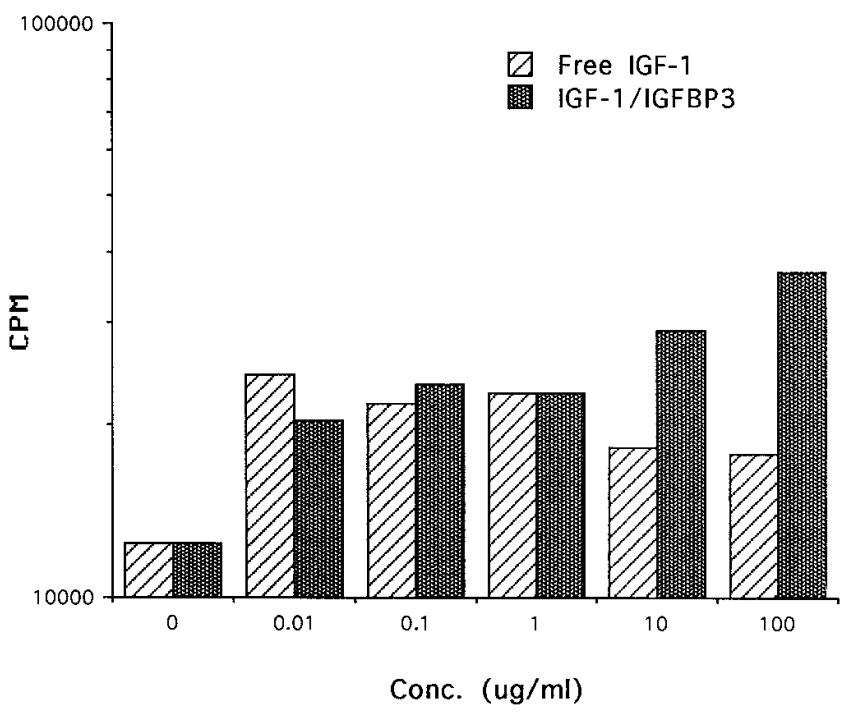

Figure 4. Effect of IGF-1 and IGF-1/IGFBP3 on MBP-specific LNC proliferation. LNC from mice immunized with MBP/CFA were stimulated with MBP $(25 \mu \mathrm{g} / \mathrm{ml})$ for $4 \mathrm{~d}$ in the presence of the indicated concentrations of IGF-1 or IGF-1/IGFBP3. Note that at each concentration, free IGF-1 represents a fivefold molar excess of IGF-1 when compared to the amount of IGF-1 present in IGF-1/IGFBP3. Bars indicate mean cpm of quadruplicate cultures. The cpm for unstimulated cells were $2,950 \pm 838$. SEM was $<15 \%$ of the mean. Data are representative of several independent experiments.

IGF-1 receptors are also expressed by lymphocytes and brain capillary endothelium, the possibility existed that IGF-1 exerted its clinical effect through its actions on cells other than oligodendrocytes, the cells which make CNS myelin (12-14, 32-34). In the present study, we have addressed the question of whether IGF-1 or IGF-1/IGFBP3 exerts an effect on EAE at those sites.

Treatment with the IGF-1/IGFBP3 complex delayed onset of disease in a dose-dependent manner (Fig. 1). Histopatho-
Table II. Transfer of EAE by MBP-specific LNC Is Not Inhibited by In Vitro Culture with IGF-1 or IGF-1/IGFBP3*

\begin{tabular}{|c|c|c|c|}
\hline In vitro treatment & $\begin{array}{l}\text { Inci- } \\
\text { dence }\end{array}$ & Day of onset ${ }^{\ddagger}$ & $\begin{array}{l}\text { Peak clinical } \\
\text { disease }^{\S}\end{array}$ \\
\hline MBP & $5 / 5$ & $6,7,7,7,8$ & $4,4,4,4,4$ \\
\hline MBP + IGF-1 $(20 \mu \mathrm{g} / \mathrm{ml})$ & $3 / 3$ & $7,6,7$ & $4,6,6$ \\
\hline $\begin{array}{l}\text { MBP + IGF-1/IGFBP3 } \\
\qquad(10 \mu \mathrm{g} / \mathrm{ml})\end{array}$ & $6 / 6$ & $7,9,10,10,13,27$ & $2,3,3,4,4,4$ \\
\hline $\begin{array}{l}\text { MBP + IGF-1/IGFBP3 } \\
\quad(100 \mu \mathrm{g} / \mathrm{ml})\end{array}$ & $7 / 8$ & $9,10,10,11,12,13,13$ & $4,4,4,4,3,3,2,0$ \\
\hline $\begin{array}{l}\text { Free IGF-1 } \\
\qquad(20 \mu \mathrm{g} / \mathrm{ml})\end{array}$ & $0 / 2$ & - & 0,0 \\
\hline $\begin{array}{l}\text { IGF-1/IGFBP3 } \\
\qquad(100 \mu \mathrm{g} / \mathrm{ml})\end{array}$ & $1 / 6$ & 20 & $2,0,0,0,0,0$ \\
\hline
\end{tabular}

*LNC from MBP/CFA-immunized animals were stimulated for $5 \mathrm{~d}$ in the presence of MBP $(25 \mu \mathrm{g} / \mathrm{ml})$ where indicated and the concentrations of IGF-1 or IGF-1/IGFBP3 indicated. Each mouse received an injection of $3 \times 10^{7}$ cells intravenously and then were monitored daily for clinical signs of EAE. ${ }^{+}$The day of disease onset for each individual mouse is shown. ${ }^{\S}$ The highest clinical score reached by each individual mouse is shown.

logic examination of these animals demonstrated that there was a lack of inflammation in the CNS of animals that had not yet developed disease, suggesting that the protective effect of IGF-1/IGFBP3 was related to the prevention of disease-causing cells from entering the CNS (Fig. 2; Table I). This observation would be in agreement with that made in the Lewis rat model, where IGF-1 reduced lesion number and area (18). However, mice that received IGF-1/IGFBP3 eventually developed severe clinical disease, with the mice receiving the highest dose of the complex exhibiting the most severe disease (Fig. 1). This suggested that administration of IGF-1/IGFBP3 also had effects which potentiated an immune response. There is evidence which suggests that administration of IGF-1 and

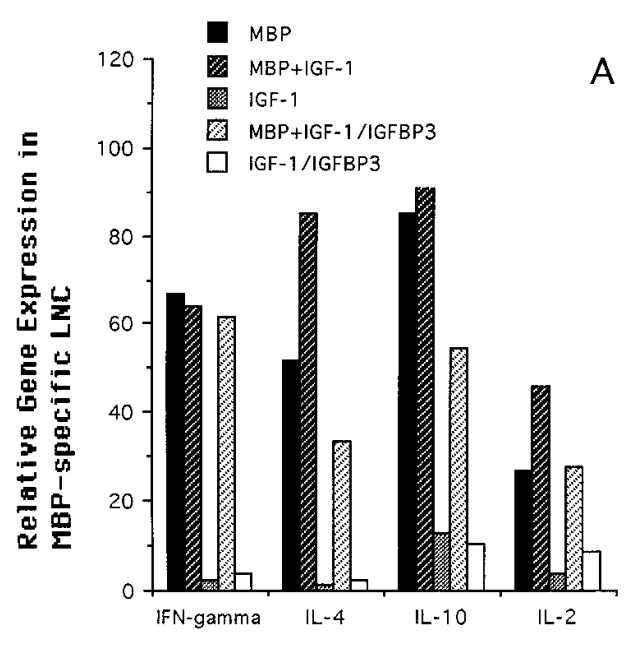

Figure 5. Cytokine gene expression after $18 \mathrm{~h}$ of culture by MBP-specific LNC cultured with MBP $(25 \mu \mathrm{g} / \mathrm{ml})$ and/or IGF-1

B $\quad(20 \mu \mathrm{g} / \mathrm{ml})$ or IGF-1/

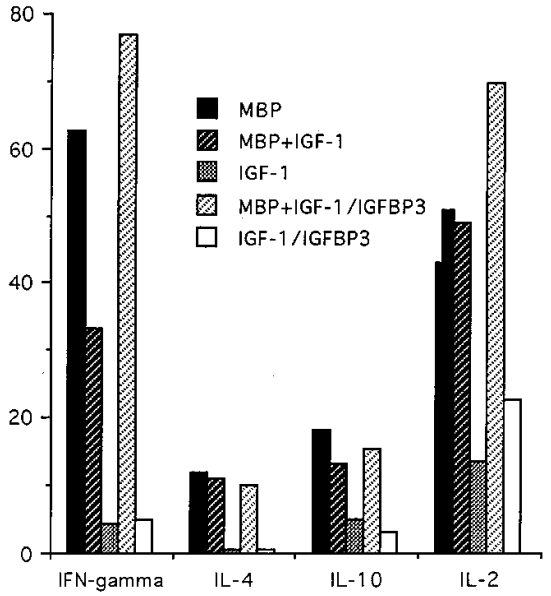
Results are expressed as relative cytokine gene expression for IFN- $\gamma$, IL-2, IL-4, and IL-10 for the conditions indicated in the legend. Cytokine gene expression was normalized to HPRT values and represents the increase in mRNA compared to unstimulated MBP-specific LNC. Data from two independent experiments are shown. 

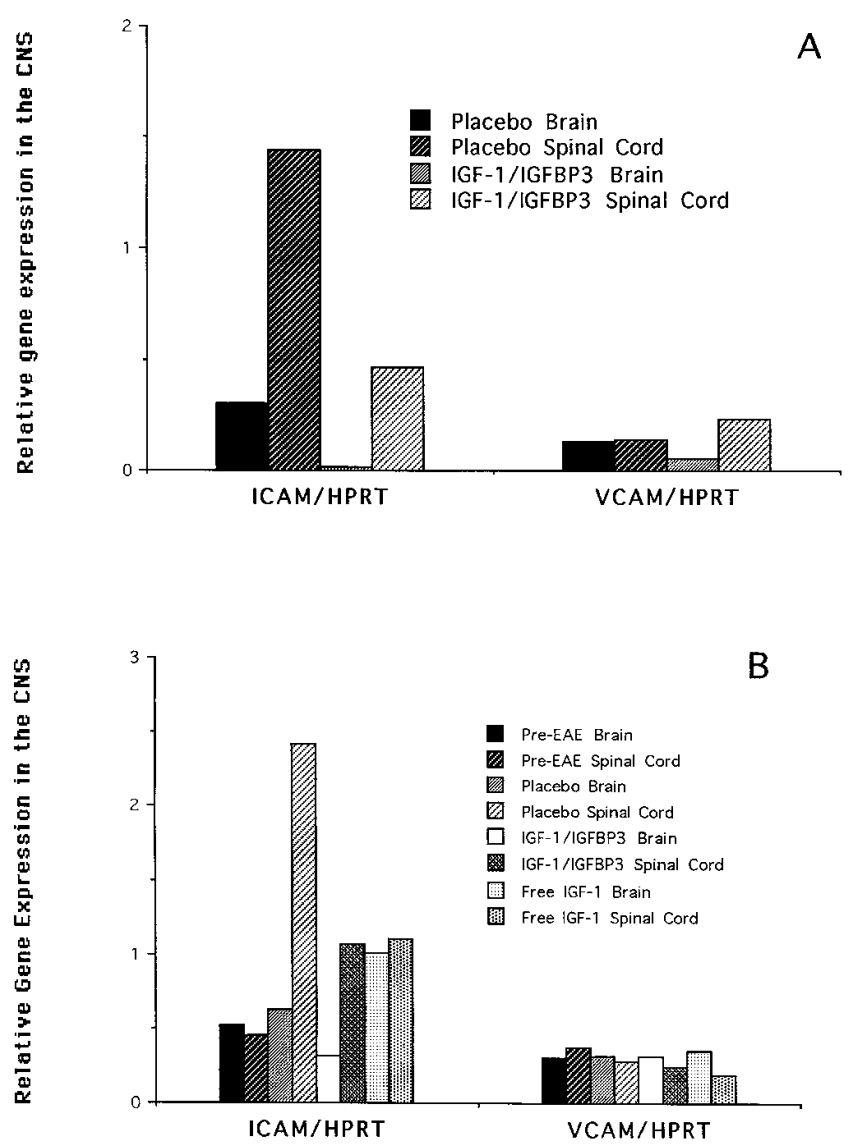

Figure 6. Adhesion molecule gene expression in the CNS in mice with passive transfer EAE. In $A$, relative levels of ICAM- 1 and VCAM-1 gene expression in the CNS were determined at 11 DPT, with mice receiving IGF-1/IGFBP3 $(50 \mathrm{mg} / \mathrm{kg}$ per day) or placebo for $10 \mathrm{~d}$. In $B$, pre-EAE samples were taken from mice 5 DPT, before clinical signs of disease. Other mice received either IGF-1 $(10 \mathrm{mg} / \mathrm{kg}$ per day), IGF-1/IGFBP3 (50 mg/kg per day), or placebo for 7 DPT, and tissues were sampled 8 DPT. Gene expression of adhesion molecules was normalized to HPRT. In both experiments, only mice that had received placebo began to exhibit clinical signs of disease.

other cytokines potentiates their effects in vivo when administered as a cytokine-antibody complex, thus administration of IGF-1 bound to its binding protein may enhance its in vivo activity through similar mechanisms (35-37).

However, the possibility exists that IGF-1 or IGF-1/ IGFBP3 administration may alter other regulatory mechanisms that occur in EAE. For example, sudden withdrawal of dexamethasone, a glucocorticoid which inhibits inflammation, can exacerbate EAE in Lewis rats if the steroid taper is not gradual (38). The present study did not examine whether IGF-1 or IGF-1/IGFBP3 altered endogenous glucocorticoid levels, which might be one of several mechanisms for how IGF-1/ IGFBP3 affects the clinical course of EAE.

To evaluate the effects of IGF-1 or IGF-1/IGFBP3 on lymphocytes, we performed antigen-specific proliferation assays using MBP-specific LNC in the presence of these reagents (Fig. 4). Addition of either IGF-1 or IGF-1/IGFBP3 enhanced the proliferative response, consistent with prior studies which had shown that IGF-1 increased thymidine incorporation by mitogen-activated $\mathrm{T}$ cells $(27,28)$. In addition, activation of
MBP-specific LNC in the presence of IGF-1 or IGF-1/IGFBP3 did not prevent their ability to transfer disease (Table II), alter their cytokine phenotype (Fig. 5), or alter their expression of relevant adhesion molecules such as LFA-1 and VLA-4 (data not shown). These data suggest that delay in the onset of disease probably did not occur at the level of the encephalitogenic $T$ cell, but does suggest the possibility that administration of IGF-1/IGFBP3 could enhance expansion of encephalitogenic $\mathrm{T}$ cells in vivo, resulting in the later enhancement of disease in animals receiving the high dose of IGF-1/IGFBP3. Future studies will address whether IGF-1 or IGF-1/IGFBP3 alters the ability of $\mathrm{T}$ cells to undergo antigen-induced programmed cell death or potentiates the phenomenon of epitope spreading (39). It is also important to note that studies examining epitope spreading must be performed in the relapsing, murine model of EAE.

The above would suggest that IGF-1 or IGF-1/IGFBP3 was acting at the level of the blood-brain barrier in preventing the early inflammation in EAE. Prior work in the Lewis rat model demonstrated not only decreased lesion size, but an actual decrease in the permeability of the blood-brain barrier in IGF-1treated rats (18). The present study also suggests that the delay in onset of disease was reflected by a decrease or absence of inflammatory cells in the CNS (Fig. 2, Table I). That brain endothelium expresses receptors for IGF-1 would also support the possibility that IGF-1 prevented disease by acting at that site (34). To investigate this further, we examined the gene expression in the CNS of two adhesion molecules implicated in EAE pathogenesis, ICAM-1 and VCAM-1. Animals that received IGF-1 or IGF-1/IGFBP3 had decreased expression of ICAM-1 without an apparent effect on VCAM-1 (Fig. 6). Although some investigators have suggested that the VLA-4/ VCAM-1 receptor-ligand pair is crucial for entry into the CNS by lymphocytes, other adhesion molecules may also play a role in the development of an inflammatory infiltrate in the CNS $(40,41)$. The changes in ICAM-1 gene expression we observed may merely reflect differences in inflammatory cell infiltration, but also provide further evidence of a mechanism for retarded entry of inflammatory cells into the CNS in mice receiving IGF-1 or IGF-1/IGFBP3. The mechanism by which IGF-1 alters vascular permeability and adhesion molecule expression is an area that will require further study.

The present study further highlights some of the important differences between the rat and murine models of EAE when evaluating therapeutic agents. Because the regulatory mechanisms in the Lewis rat model are so profound as to prevent most relapses from occurring, therapies need only be effective for a short period of time. As demonstrated in this study, therapies that initially appear beneficial may have dramatically different outcomes when used in a relapsing disease model. These observations need to be considered when deciding whether an agent such as IGF-1 or IGF-1/IGFBP3 should be tested in a relapsing-remitting human disease such as multiple sclerosis.

In summary, IGF-1 appeared to have more profound biologic effects both in vitro and in vivo when delivered as part of the IGF-1/IGFBP3 complex than as free IGF-1 alone. This would suggest that binding of IGF-1 to its binding proteins may not necessarily always antagonize the effects of IGF-1 as others have proposed (34). This increase in bioactivity is most likely due to an increase in its biologic half-life and that IGFbinding proteins may be involved in IGF-1 transport across en- 
dothelial barriers in vivo $(22,34)$. Thus, understanding of the pleiotrophic activities of a molecule such as IGF-1 may be enhanced when administered under such conditions of altered pharmacokinetic properties, such as when it is bound to its binding protein. These pleiotrophic activities should be considered before the treatment of conditions such as multiple sclerosis, which most likely has a variety of pathogenic processes contributing to the final clinical outcome.

\section{Acknowledgments}

The authors thank S. Brocke and H.F. McFarland (both from National Institutes of Health, Bethesda, MD) for helpful comments and reading the manuscript.

This work was supported by grants from the National Multiple Sclerosis Society to A.H. Cross and M.K. Racke. A.E. Lovett-Racke was supported as a Lucille P. Markey Pathway postdoctoral fellow. M.K. Racke is the Young Investigator in Multiple Sclerosis of the American Academy of Neurology Education and Research Foundation.

\section{References}

1. Martin, R., H.F. McFarland, and D.E. McFarlin. 1992. Immunological aspects of demyelinating diseases. Annu. Rev. Immunol. 10:153-187.

2. Pettinelli, C.B., and D.E. McFarlin. 1981. Adoptive transfer of experimental allergic encephalomyelitis in $\mathrm{SJL} / \mathrm{J}$ mice after in vitro activation of lymph node cells by myelin basic protein: requirement for Lyt $1+2-$ lymphocytes. J. Immunol. 127:1420-1423.

3. Racke, M.K., S. Dhib-Jalbut, B. Cannella, P.S. Albert, C.S. Raine, and D.E. McFarlin. 1991. Prevention and treatment of chronic relapsing experimental allergic encephalomyelitis by transforming growth factor- $\beta 1$. J. Immunol. 146:3012-3017.

4. Racke, M.K., A. Bonomo, D.E. Scott, B. Cannella, A. Levine, C.S. Raine, E.M. Shevach, and M. Rocken. 1994. Cytokine-induced immune deviation as a therapy for inflammatory autoimmune disease. J. Exp. Med. 180:19611966.

5. Acha-Orbea, H., D.J. Mitchell, L. Timmerman, D.C. Wraith, G.S. Tausch, M.K. Waldor, S.S. Zamvil, H.O. McDevitt, and L. Steinman. 1988. Limited heterogeneity of $\mathrm{T}$ cell receptors from lymphocytes mediating autoimmune encephalomyelitis allows specific immune intervention. Cell. 54:263-273.

6. Urban, J.L., V. Kumar, D.H. Kono, C. Gomez, S.J. Horvath, J. Clayton, D.G. Ando, E.E. Sercarz, and L. Hood. 1988. Restricted use of T cell receptor $\mathrm{V}$ genes in murine autoimmune encephalomyelitis raises possibilities for antibody therapy. Cell. 54:577-592.

7. Vandenbark, A.A., G. Hashim, and H. Offner. 1989. Immunization with a synthetic T-cell receptor V-region peptide protects against experimental allergic encephalomyelitis. Nature. 341:541-544.

8. Howell, M.D., S.T. Winters, T. Olee, H.C. Powell, D.J. Carlo, and S.W. Brostoff. 1989. Vaccination against experimental allergic encephalomyelitis with T cell receptors peptides. Science. 246:668-670.

9. Brocke, S., K. Gijbels, M. Allegretta, I. Ferber, C. Piercy, T. Blankenstein, R. Martin, U. Utz, N. Karin, D. Mitchell, et al. 1996. Treatment of experimental encephalomyelitis with a peptide analogue of myelin basic protein. $\mathrm{Na}$ ture. 379:343-346.

10. Cohick, W.S., and D.R. Clemmons. 1993. The insulin-like growth factors. Annu. Rev. Physiol. 55:131-153.

11. Leroith, D. 1997. Insulin-like growth factors. New Engl. J. Med. 336: 633-640.

12. Mozell, R.L., and F.A. McMorris. 1991. Insulin-like growth factor I stimulates oligodendrocyte development and myelination in rat brain aggregate cultures. J. Neurosci. Res. 30:382-390.

13. McMorris, F.A., T.M. Smith, S. DeSalvo, and R.W. Furlanetto. 1986. Insulin-like growth factor I/somatomedin C: a potent inducer of oligodendrocyte development. Proc. Natl. Acad. Sci. USA. 83:822-826.

14. Roth, G.A., V.H. Jorgensen, and M.B. Bornstein. 1985. Effect of insulin, proinsulin and pancreatic extract on myelination and remyelination in organotypic nerve tissue in culture. J. Neurol. Sci. 71:339-350.

15. Beck, K.D., L. Powell-Braxton, H.-R. Widmer, J. Valverde, and F. Hefti. 1995. Igf1 gene disruption results in reduced brain size, CNS hypomyelination, and loss of hippocampal granule and striatal parvalbumin-containing neurons. Neuron. 14:717-730.

16. Carson, M.J., R.R. Behringer, R.L. Brinster, and F.A. McMorris. 1993. Insulin-like growth factor I increases brain growth and central nervous system myelination in transgenic mice. Neuron. 10:729-740.
17. Komoly, S., L.D. Hudson, H.deF. Webster, and C.A. Bondy. 1992. Insulin-like growth factor I gene expression is induced in astrocytes during experimental demyelination. Proc. Natl. Acad. Sci. USA. 89:1894-1898.

18. Liu, X., D.-L. Yao, and H.deF. Webster. 1995. Insulin-like growth factor I treatment reduces clinical deficits and lesion severity in acute demyelinating experimental autoimmune encephalomyelitis. Multiple Sclerosis. 1:2-9.

19. Liu, X., D.-L. Yao, C.A. Bondy, M. Brenner, L.D. Hudson, J. Zhou, and H.deF. Webster. 1994. Astrocytes express insulin-like growth factor-I (IGF-I) and its binding protein, IGFBP-2, during demyelination induced by experimental autoimmune encephalomyelitis. Mol. Cell. Neurosci. 5:418-430.

20. Yao, D.-L., X. Liu, L.D. Hudson, and H.deF. Webster. 1995. Insulin-like growth factor I treatment reduces demyelination and up-regulates gene expression of myelin-related proteins in experimental autoimmune encephalomyelitis. Proc. Natl. Acad. Sci. USA. 92:6190-6194.

21. Yao, D.-L., N.R. West, C.A. Bondy, M. Brenner, L.D. Hudson, J. Zhou, G.H. Collins, and H.deF. Webster. 1995. Cryogenic spinal cord injury induces astrocytic gene expression of insulin-like growth factor I and insulin-like growth factor binding protein 2 during myelin regeneration. J. Neurosci. Res. 40:647-659.

22. Adams, S., J. Moore, S. Chu, C. Bagi, L. DeLeon, C. Liu, D. Schmidt, and A. Sommer. 1995. Pharmacokinetics and bioavailability of hIGF-I/IGFBP-3 in the rat and monkey. Prog. Growth Factor Res. 6:347-356.

23. Kolaczynski, J.W., and J.F. Caro. 1994. Insulin-like growth factor-1 therapy in diabetes: physiologic basis, clinical benefits, and risks. Ann. Int. Med. 120:47-55.

24. Lewis, M.E., N.T. Neff, P.C. Contreras, D.B. Stong, R.W. Oppenheim, P.E. Grebow, and J.L. Vaught. 1993. Insulin-like growth factor-1: potential for treatment of motor neuronal disorders. Exp. Neurol. 124:73-88.

25. Deibler, G.E., R.E. Martenson, and M.W. Kies. 1972. Large scale preparation of myelin basic protein from central nervous system tissue of several mammalian species. Prep. Biochem. 2:139-165.

26. Sommer, A., C.A. Maack, S.K. Spratt, D. Mascarenhas, T.J. Tressel, E.T. Rhodes, R. Lee, M. Roumans, G.P. Tatsuno, J.A. Flynn, et al. 1991. Molecular genetics and actions of recombinant insulin-like growth factor binding protein-3. In Modern Concepts of Insulin-Like Growth Factors. E.M. Spencer, editor. Elsevier, New York. 715-728.

27. Lindsey, J.W., and L. Steinman. 1993. Competitive PCR quantification of CD4, CD8, ICAM-1, VCAM-1, and MHC class II mRNA in the central nervous system during development and resolution of experimental allergic encephalomyelitis. J. Neuroimmunol. 48:227-234.

28. Svetic, A., F.D. Finkelman, Y.C. Jian, C.W. Dieffenbach, D.E. Scott, K.F. McCarthy, A.D. Steinberg, and W.C. Gause. 1991. Cytokine gene expression after in vivo primary immunization with goat antibody to mouse IgD antibody. J. Immunol. 147:2391-2397.

29. Cross, A.H., T.J. Girard, K.S. Giacoletto, R.J. Evans, R.M. Keeling, R.F. Lin, J.L. Trotter, and R.W. Karr. 1995. Long-term inhibition of murine experimental autoimmune encephalomyelitis using CTLA-4-Fc supports a key role for CD28 costimulation. J. Clin. Invest. 95:2783-2789.

30. Moore, G.R.W., U. Traugott, M. Farooq, and C.S. Raine. 1984. Experimental autoimmune encephalomyelitis: augmentation of demyelination by different myelin lipids. Lab. Invest. 51:416-424.

31. Morrison, D.F. 1976. Multivariate Statistical Methods. McGraw-Hill, New York. 128-141.

32. Clark, R., J. Strasser, S. McCabe, K. Robbins, and P. Jardieu. 1993. Insulin-like growth factor-1 stimulation of lymphopoiesis. J. Clin. Invest. 92:540-548.

33. Tapson, V.F., M. Boni-Schnetzler, P.F. Pilch, D.M. Center, and J.S. Berman. 1988. Structural and functional characterization of the human T lymphocyte receptor for insulin-like growth factor I in vitro. J. Clin. Invest. 82:950-957.

34. Reinhardt, R.R., and C.A. Bondy. 1994. Insulin-like growth factors cross the blood-brain barrier. Endocrinology. 135:1753-1761.

35. Pell, J.M., H.C. Flick-Smith, S. Dye, and R.A. Hill. 1995. Further characterization of an IGF-1 enhancing antibody: actions on IGF-1-induced hypoglycaemia and interaction with the analogue LR3IGF-1. Prog. Growth Factor Res. 6:367-375.

36. Hill, R.A., H.C. Flick-Smith, S. Dye, and J.M. Pell. 1997. Actions of an IGF-1-enhancing antibody on IGF-1 pharmacokinetics and tissue distribution increased IGF-1 bioavailability. J. Endocrinol. 152:123-130.

37. Finkelman, F.D., K.B. Madden, S.C. Morris, J.M. Holmes, N. Boiani, I.M. Katona, and C.R. Maliszewski. 1993. Anti-cytokine antibodies as carrier proteins: prolongation of in vivo effects of exogenous cytokines by injection of cytokine-anti-cytokine antibody complexes. J. Immunol. 151:1235-1244.

38. Reder, A.T., M. Thapar, and M.A. Jensen. 1994. A reduction in serum glucocorticoids provokes experimental allergic encephalomyelitis: implications for treatment of inflammatory brain disease. Neurology. 44:2289-2294.

39. Lehmann, P.V., T. Forsthuber, D. Miller, and E.E. Sercarz. 1992. Spreading of T cell autoimmunity to cryptic determinants of an autoantigen. Nature. 358:155-157

40. Baron, J.L., J.A. Madri, N.H. Ruddle, G. Hashim, and C.A. Janeway, Jr. 1993. Surface expression of $\alpha 4$ integrin by CD4 T cells is required for their entry into brain parenchyma. J. Exp. Med. 177:57-68.

41. Cannella, B., A.H. Cross, and C.S. Raine. 1990. Upregulation and coexpression of adhesion molecules correlate with relapsing autoimmune demyelination in the central nervous system. J. Exp. Med. 172:1521-1524. 